\title{
Today's Competitive Objective: Augmenting Human Performance
}

\author{
Kay M. Stanney and Kelly S. Hale \\ Design Interactive, Inc. \\ 1221 E. Broadway, Suite 110 \\ Oviedo, FL 32765 USA \\ \{Kay.Stanney, Kelly.Hale\}@DesignInteractive.net
}

\begin{abstract}
Gaining competitive advantage requires acquiring or developing a capability that allows an organization or individual to outperform its competitors. In today's technology-driven environment, where human capabilities are struggling to keep up with technology offerings, techniques for augmenting human performance are becoming the critical gap that is precluding realizing the full benefits that these technology advances have to offer. The challenge is thus to develop tools and techniques that augment the human potential in order to best couple it to advancing complex interactive systems. In this void, those who are developing the capability to support real-time measurement, diagnosis, and augmentation of human performance may be the first to gain the competitive edge.
\end{abstract}

Keywords: Augmented cognition, Adaptive systems, human performance.

As natural human capacities become increasingly mismatched to data volumes, processing capabilities, and decision speeds, augmenting human performance will become essential for gaining the benefits that other technology advances can offer.

Technology Horizons: A Vision for Air Force Science \& Technology During 2010-2030

Werner J.A. Dahm, United States Air Force Chief Scientist

May 15, 2010 (p. 58)

\section{Introduction}

The concept of human performance augmentation is not new. Efforts to enhance human performance have a long evolutionary history (Spohrer, 2002), which commenced millions of years ago with the human brain evolving its reasoning abilities, followed approximately one hundred thousand generations ago with the introduction of widespread spoken language and then the introduction of tools ten thousand generations ago; creative arts and written language appeared about 500 
generations ago; over the past few hundred generations we have seen libraries and universities appear, along with printing presses, clocks, telephones, assembly lines, radios, televisions, computers, and the Internet. All of these advances have enhanced the human's ability to perform their intended tasks - allowing humans to reach beyond their innate abilities - by taking an "outside-in" tactic (i.e., providing external aiding devices) (see Figure 1). With the advent of computers in general, and the information age specifically, the realities of exceeding the limits of human capabilities - even given the performance augmentations that evolved up to the information age - have become manifest.

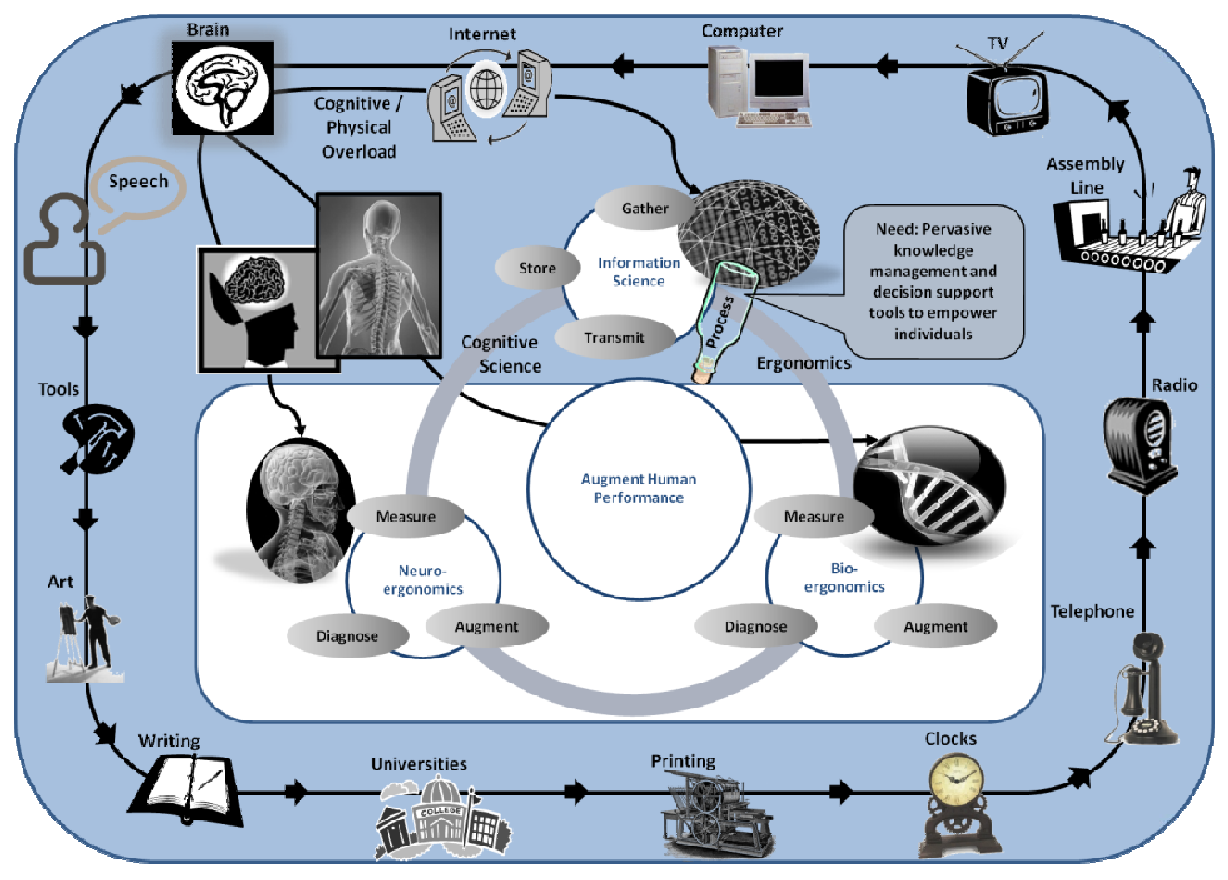

Fig. 1. Evolutionary history of human performance augmentation

\section{The Augmentation Challenge}

...there are many examples of systems that have either failed entirely or have been adopted despite their inadequacies because of the need for their capabilities. Often the reasons these adopted systems were considered unsuccessful are because they failed to meet the requirements of the human users-they required unreasonable workload, induced psychological and physical stress, or resulted in costly human error. They failed because their developers had inadequate understanding of, or overlooked consideration of, the unique capacities and limitations of people.

Pew \& Mavor, 2007 (p. 12) 
Initially, the mismatch between system and human was addressed in the conventional manner of performance augmentation - by providing external aids. Specifically, the field of information science emerged and provided technologies that directed how best to gather, store, transmit, and process information (Roco \& Bainbridge, 2002). The resulting bottleneck to performance augmentation resulting from the information sciences was the "process" stage - while the information sciences brought the capabilities to inundate operators with massive data and work long, extended hours as one can work anytime, anyplace, these new capabilities are exceeding the human's capabilities to process (both cognitively and physically) at these higher levels. To address this bottleneck, the field of ergonomics first rose to the challenge and provided design principles that focused on redesigning information systems so that the physical stress on the operator was reduced; followed by the field of cognitive science, which introduced design principles that focused on redesigning the user interface to enhance information throughput, thereby reducing cognitive load (Stanney, 2010).

Yet, persistent challenges to human capabilities - such as sustained operations, environmental ambiguity, and information overload - require a new type of human performance augmentation- one set apart from its predecessors by the fact that it works from the "inside-out." Rather than the external performance aids of the past few hundred generations that store and make information accessible when needed to plan, inform, and guide (Rossett \& Schafer, 2006), or the more recent solutions that support the physical and cognitive aspects of interaction with information systems(Stanney et al, 2001), contemporary forms of augmentation are delving inward - peering into the brain and body to measure and model human states that can be augmented in real-time so that the human can handle larger physical and cognitive loads. To realize this objective, two fields have emerged - neuroergonomics, which seeks to develop means of translating neural signals into computational cognitive models that trigger cognitive performance enhancements, and bioergonomics, which seeks to develop means to real-time monitor an individual's health in terms of physical stress and physiological condition and trigger administration of cognitive performance enhancing drugs or other such supplements (Stanney, 2010). Taken together these fields aim to overcome the nettlesome challenge of the information age - to provide pervasive knowledge management and decision support tools that truly empower individuals (see Figure 1).

Licklider (1960, pp. 4-5) envisioned such internally-driven performance enhancement a half century ago, when he mused:

that, in not too many years, human brains and computing machines will be coupled together very tightly, and that the resulting partnership will think as no human brain has ever thought and process data in a way not approached by the information-handling machines we know today.

Today industry is seeking to advance the level of maturity of such coupled systems. Whether it is to support stock market analysts aiming to achieve competitive intelligence to maximize gains, physicians mining massive data to uncover important and reliable relationships between symptoms and diagnoses, or Commanders uncovering their adversary's intent through mining daily message traffic, the ability to 
augment natural human capacities that are being outstripped by increasing data volumes, processing capabilities, and decision speeds is becoming essential for gaining a competitive advantage. In this regard, a number of advances have been made over the past decade that have brought us closer to operational systems that can support real-time measurement, diagnosis, and augmentation of human performance based on physiological data.

\section{Physiologically-Based Human Performance Augmentation}

Table 1 provides an overview of the current technology maturity levels of neuroergonomic and bioergonomic technologies that aim to augment human performance in terms of Technology Readiness Levels (TRLs), which measure the maturity of evolving technologies (DOD, 2009). TRLs range from level one, where basic principles are being observed and reported, to mid-levels four and five, where component validation in laboratory and applied relevant environments occurs, to a high level of nine, where a full-scale system is proven successful in an operational setting.

Table 1. Technology Readiness Level of Neuroergonomic and Bioergonomic Technologies

\begin{tabular}{|c|c|c|c|c|}
\hline & TRL 2-3 & TRL 3-5 & TRL 5-6 & TRL 6-8 \\
\hline \multicolumn{5}{|l|}{ Neuroergonomics } \\
\hline Measure & & $\begin{array}{l}\text { fNIR, Posture, } \\
\text { Pupilometry }\end{array}$ & $\begin{array}{l}\text { EDR, EEG, } \\
\text { EMG, GSR, } \\
\text { Respiration } \\
\end{array}$ & $\begin{array}{c}\text { ECG, Eye/ } \\
\text { Gaze } \\
\text { Tracking } \\
\end{array}$ \\
\hline Diagnosis & & $\begin{array}{c}\text { Neuro- } \\
\text { physiologically } \\
\text { Informed ICA } \\
\end{array}$ & & \\
\hline Augment & & $\begin{array}{c}\text { Presentation, } \\
\text { Schedule, System } \\
\text { Autonomy }\end{array}$ & & \\
\hline \multicolumn{5}{|l|}{ Bioergonomics } \\
\hline Measure & $\begin{array}{l}\text { Real-time } \\
\text { Blood and } \\
\text { Tissue } \\
\text { Analysis } \\
\end{array}$ & & $\begin{array}{c}\text { Salivary } \\
\text { Cortisol, } \mathrm{SpO}_{2} \\
\text { Oximetry }\end{array}$ & \\
\hline Diagnosis & & $\begin{array}{c}\text { Generalized } \\
\text { Biomathematical } \\
\text { Models } \\
\end{array}$ & & \\
\hline Augment & & $\begin{array}{l}\text { Auto-dispense } \\
\text { Performance- } \\
\text { Enhancing Drugs } \\
\text { and Supplements }\end{array}$ & & \\
\hline
\end{tabular}

\subsection{Measurement Component}

The current maturity of neuroergonomic measurements tools ranges from TRL 3-5 (technology development; e.g., functional near infrared Imaging [fNIR], posture 
tracking, pupilometry) to TRL 5-6 (technology demonstration; e.g., electrodermal response [EDR], EEG, electromyograph [EMG], galvanic skin response [GSR]) to TRL 6-8 (system/subsystem development; e.g., electrocardiogram [ECG], eye/gaze tracking) (Schnell et al., 2008). The maturity of bioergonomic measurement tools ranges from TRL 3-5 (e.g., real-time blood and tissue chemistry analysis; Merrill, 2009) to TRL 5-6 (e.g., real-time salivary cortisol). Several efforts have demonstrated real-time cognitive and biological state measures over the past decade that meet the requirements of (1) sensitivity to different brain states and/or processes, (2) reliability, and (3) practicality in fielded use (Stanney, Schmorrow, \& Hale, 2010). The current challenge with cognitive state measurement is in developing means to substantially advance real-time data fusion and classifier construction techniques (Fidopiastis \& Wiederhold, 2009; Hale, Stanney, \& Schmorrow, 2010). The current challenge for biological state measurement is in advancing real-time blood and tissue chemistry analysis for monitoring physical stress and physiological condition (Merrill, 2009).

\subsection{Diagnostic Component}

The current maturity of both neuroergonomic and bioergonomic diagnostic tools is a TRL 3-5 level, that of technology development. Most research into automated human performance augmentation has been conducted in the context of intelligent tutoring systems (see reviews by Murray, 1999 and Corbett et al., 2001), but these systems are often associated with high costs for knowledge engineering and implementation (Stevens et al., 2009). From a cognitive state perspective, the current challenge is to use machine learning to automatically produce models of expert behavior for automated performance assessment (Abbott, 2006; Santarelli et al., 2009; Stevens et al., 2009, 2010), as well as to combine multiple component models of cognitive performance into an integrative computational model (Santarelli et al., 2009), while ensuring the resulting models can provide accurate assessments on complex realworld tasks. From a biological state perspective, most research to date has resulted in sophisticated biomathematical models that can be used to create and assess work-rest schedules (Dean et al., 2007; Hursh et al., 2006). These models are limited to making general predictions about relative alertness in a post hoc manner (Van Dongen, 2004) or to making specific a priori predictions regarding the impact of fatigue (e.g., cognitive slowing; cognitive lapses) on cognitive performance (Gunzelmann, et al., 2009). Thus, the challenge to biological state diagnosis is to develop generative computational models that can make real-time predictions about the consequences of physical fatigue and other physiological stressors to cognitive performance in realworld settings.

\subsection{Augmentation Component}

The current maturity of both neuroergonomic and bioergonomic augmentation tools is a TRL 3-5 level, that of technology development, as much work has been done to identify "when, what, and how" to augment human performance in terms of adaptations of information presentation and schedule, level of system autonomy, and 
use of performance enhancing supplements or drugs (Fuchs et al., 2007; Stanney, 2010). The current challenges are to empirically identify the most effective individually tailored performance augmentations, as well as to develop trusted, adaptable, and flexible task allocation schemes and seamless and elegant interruption management strategies that not only consider the cognitive and biological states of the operator or trainee, but also individual learning/operating styles, preferences, and physiological predispositions that may develop over time as the system is being used.

\section{Conclusions}

While efforts to enhance human performance have a long evolutionary history from tools to libraries to clocks and gadgets to computers and the Internet, the quest to realize the human potential from the "outside-in" has been ever-present. This review of neuroergonomic and bioergonomic technologies that aim to support a paradigm shift in human performance augmentation by taking an "inside-out" approach, demonstrates that while substantial progress has been made in developing and validating these technologies, considerable work is still needed to realize fullscale systems that prove successful in operational, real-world settings. Those who propel these advancements are likely to gain a competitive advantage and be in position to outthink their competitors, outlearn their colleagues, and outsmart their adversaries.

\section{References}

1. Abbott, R.G.: Automated expert modeling for automated student evaluation. Intelligent Tutoring Systems 4053, 1-10 (2006)

2. Corbett, A.T., Koedinger, K.R., Hadley, W.H.: Cognitive tutors: From the research classroom to all classrooms. In: Goodman, P.S. (ed.) Technology enhanced learning: Opportunities for change, pp. 235-263. Lawrence Erlbaum, Mahwah (2001)

3. Dean II, D.A., Fletcher, A., Hursh, S.R., Klerman, E.B.: Developing mathematical models of neurobehavioral performance for the real world. Journal of Biological Rhythms 22, 246-258 (2007)

4. Department of Defense (DOD; Technology Readiness Assessment (TRA) Deskbook. (July 2009),

http://www.dod.mil/ddre/doc/DoD_TRA_July_2009_Read_Version.pdf

5. Fidopiastis, C.M., Weiderhold, M.: Mindscape retuning and brain reorganization with hybrid universes: The future of virtual rehabilitation. In: Schmorrow, D., Cohn, J., Nicholson, D. (eds.) The PSI Handbook of Virtual Environments for Training \& Education: Developments for the Military and Beyond, pp. 427-434. Praeger Security International, Westport (2008)

6. Fuchs, S., Hale, K.S., Stanney, K.M., Juhnke, J., Schmorrow, D.: Enhancing mitigation in augmented cognition. Journal of Cognitive Engineering and Decision Making 1(3), 309326 (2007)

7. Gunzelmann, G., Byrne, M.D., Gluck, K.A., Moore, L.R.: Using computational cognitive modeling to predict dual-task performance with sleep deprivation. Human Factors 51(2), 251-260 (2009) 
8. Hale, K.S., Stanney, K.M., Schmorrow, D.D.: Augmenting cognition in HCI: 21st century adaptive system science and technology. In: Jacko, J., Sears, A. (eds.) Handbook of Human-Computer Interaction, 3rd edn. CRC Press, Boca Raton (2010)

9. Hursh, S.R., Raslear, T.G., Kaye, A.S., Fanzone, J.F. (2006). Validation and Calibration of a Fatigue Assessment Tool for Railroad Work Schedules, Summary Report. U.S. Department of Transportation Report Number: DOT/FRA/ORD-06/21, October 31 (2006), http: / /www. fra.dot.gov/downloads/Research/ord0621.pdf.

10. Licklider, L.C.R.: Man-computer symbiosis. IRE Transactions on Human Factors in Electronics 1, 4-11 (1960), http: / /www. memex.org/licklider.pdf

11. Merrill, M.: Monitoring technology being developed for astronauts could benefit patients on Earth. Healthcare IT News (April 30, 2009),

http: / / www . heal thcareitnews. com/news/monitoring-technologybeing-developed-astronauts-could-benefit-patientsearth. (Accessed February 22, 2010)

12. Murray, T.: Authoring intelligent tutoring systems: An analysis of the state of the art. International Journal of Artificial Intelligence in Education 10, 98-129 (1999)

13. Pew, R.W., Mavor, A.S.: Human-system integration in the system development process: A new look., 11893th edn. The National Academies Press, Washington, DC (2007), http: / / www. nap.edu/catalog.php?record_id=11893 (accessed January 6, 2010)

14. Roco, M.C., Bainbridge, W.S. (eds.): Converging technologies for improving human performance (2010),

http: / / www.wtec.org/ConvergingTechnologies / Report/

NBIC_report.pdf (accessed September 28, 2010)

15. Rossett, A., Schafer, L.: Job aids and performance support: moving from knowledge in the classroom to knowledge everywhere. Pfeiffer, CA (2006)

16. Santarelli, T., Maulitz, R., Zachary, W., Barnieu, J., O'Connor, B.: Training Healthcare Providers to Confront Diversity in Clinical Settings. In: The Proceedings of the Interservice/Industry Training, Simulation, and Education Conference (I/ITSEC 2009). National Training Systems Association, VA (2009)

17. Schnell, T., Keller, M., Poolman, P.: Quality of training effectiveness assessment (QTEA): A neurophysiologically based method to enhance flight training. In: IEEE/AIAA 27th Digital Avionics Systems Conference, St. Paul, MN, October 26-30 (2008)

18. Spohrer, J.: NBICs (nano-bio-info-cogno-socio) convergence to improve human performance: opportunities and challenges. In: Roco, M.C., Bainbridge, W.S. (eds.) Converging Technologies for Improving Human Performance, Chapter B, pp. 101-117 (2002); NSF/DOC-sponsored report, http: / / www . wtec .org/ConvergingTechnologies / Report/ NBIC_report.pdf (accessed September 28, 2010)

19. Stanney, K.M.: Augmenting human performance. In: Fafrowicz, M., Marek, T., Karwowski, W., Schmorrow, D. (eds.) Neuroadaptive Systems: Research, Theory, and Applications. Taylor \& Francis/CRC Press (2010) (in press)

20. Stanney, K.M., Schmorrow, D., Hale, K.: Neuroergonomics and augmented cognition. In: Salvendy, G. (ed.) Handbook of human factors and ergonomics, 4th edn. John Wiley, New York (2010) (in press)

21. Stanney, K.M., Smith, M.J., Carayon, P., Salvendy, G.: Human-computer interaction. In: Salvendy, G. (ed.) Handbook of Industrial Engineering, 3rd edn., pp. 1192-1236. John Wiley, New York (2001) 
22. Stevens, S.M., Forsythe, J.C., Abbott, R.G., Gieseler, C.J.: Experimental assessment of accuracy of automated knowledge capture. In: Schmorrow, D.D., Estabrooke, I.V., Grootjen, M. (eds.) FAC 2009. LNCS, vol. 5638, pp. 212-216. Springer, Heidelberg (2009)

23. U.S. Air Force Chief Scientist (AF/ST) (2010), Technology Horizons: A Vision for Air Force Science \& Technology During 2010-2030. AF/ST-TR-10-01-PR (May 15, 2010), http://www.af .mil/shared/media/document/AFD-100727-053.pdf

24. Van Dongen, H.P.A.: Comparison of mathematical model predictions to experimental data of fatigue and performance. Aviation, Space, and Environmental Medicine 75(3), A15A36 (2004) 